Polymer Journal, Vol. 39, No. 8, pp. 813-821 (2007)

(C) 2007 The Society of Polymer Science, Japan

\title{
Synthesis of Tropolone-Containing Conjugated Polymers and Their Optical Properties
}

\author{
Koji TAKagI ${ }^{\dagger}$ Kazuhiro SAIKI, Kousuke Mori, Yasuo YUKI, and Masato SUZUKI \\ Department of Materials Science and Engineering, Graduate School of Engineering, Nagoya Institute of Technology, \\ Gokiso-cho, Showa-ku, Nagoya 466-8555, Japan
}

(Received April 5, 2007; Accepted April 26, 2007; Published June 12, 2007)

\begin{abstract}
A novel dibromo methyltropolone monomer (an isomeric mixture) was synthesized by the nucleophilic reaction to 2,4,7-tribromotropone. Methyltropolone-containing conjugated polymers were successfully obtained by Suzuki coupling, Mizoroghi-Heck, and Sonogashira coupling reactions. The $\mathrm{C}=\mathrm{O}$ stretching vibration signals shifted to the lower frequency region as compared with a monomer. The conversion from the methoxy group to the hydroxyl group was performed by the polymer reaction using $\mathrm{LiI}$ or $\mathrm{BBr}_{3}$. The soluble conjugated polymers could be obtained from those bearing 9,9-dihexyl-2,7-fluorenylidene and 2,5-didecyl-1,4-phenylene segments. The formation of an intramolecular hydrogen bond was confirmed by the shift of the $\mathrm{C}=\mathrm{O}$ vibration signal to the lower frequency region. In the UV and PL spectra, the maximum wavelengths were dependent upon the chemical structure of linkage and the presence of donor-acceptor interaction. The formation of an intramolecular hydrogen bond brought about the red shift of the absorption spectra and the quench of the fluorescence emission. [doi:10.1295/polymj.PJ2007003]

KEY WORDS Tropolone / Conjugated Polymer / Hydrogen Bond / Optical Properties /
\end{abstract}

Since conjugated polymers and oligomers have been attracted increasing attention for the application to light-emitting diodes, plastic lasers, and sensors, those with a novel structure were successively produced for the past decade. However, the relation between the device performance and the material structure is still a subject of discussion. Thus the fine control and tuning of optical properties of conjugated polymers are important topic to obtain photonic devices composed of these photoactive polymer materials. ${ }^{1}$ The chemical modification of the polymer repeating unit is the direct method to modulate the effective conjugation length, which eventually influences the macromolecular optoelectronic properties such as emissive color, fluorescence quantum yield, and redox potential. In most of conjugated polymers, 5 and 6membered aromatic rings with the $6 \pi$ electron system like benzene, thiophene, pyridine, and 1,3-oxazole are the component of the main chain. To gain further insight into the fundamental photophysics of conjugated polymers and to develop novel functional materials made from these polymers, the production of polymers having the segment with much different electronic character might be one of the challenging effort. ${ }^{2}$

Recently, we have reported the synthesis of a series of tropone-containing conjugated polymers. ${ }^{3}$ The photophysical properties of polymer were strongly dependent upon the chemical structure of tropone unit. For example, the absorption maximum wavelength of a $p$-phenylenevinylene polymer containing tropone was observed at $515 \mathrm{~nm}$, which dramatically red shift- ed by $c a .80 \mathrm{~nm}$ from a similar polymer containing benzotropone. ${ }^{3 \mathrm{e}}$ The conjugated polymer bearing benzotropone showed a quasi-reversible protonation-deprotonation cycle as evidenced by the UV spectroscopy that was supposed to be the character of the carbonyl group of benzotropone. ${ }^{3 \mathrm{c}}$ To this end, we directed our attention to the synthesis of conjugated polymers bearing tropolone in the main chain. Tropone is predicted to have a nonplanar bent structure and the orbital interaction between p-orbital is considered to be less effective. ${ }^{4}$ On the other hand, some tropolone derivatives demonstrate [1,9]-sigmatropy rearrangement to have a large dipole moment and have a rigid planar structure useful as the mesogenic core in the liquid crystalline materials. ${ }^{5}$ Accordingly, the optical properties of conjugated polymer bearing tropolone are believed to be quite different from those bearing (benzo)tropone. Tropolone with a free hydroxyl group could form an intramolecular hydrogen bond to behave as a bicyclic compound with fused 5 and 7-membered rings similar to azulene. ${ }^{6}$ The conjugated polymers including an intramolecular hydrogen bond in the repeating unit have been prepared, where the hydrogen bond formation enhanced the electron delocalization along the main chain and brought about a red shift of the absorption spectra. ${ }^{7}$ These polymers not only exhibited different absorption spectra but also demonstrated the stimuli responsive properties. $^{7 \mathrm{~d}-\mathrm{f}}$ Hence the influence of an intramolecular hydrogen bond within tropolone unit upon the optical properties of conjugated polymer is also of much interest.

${ }^{\dagger}$ To whom correspondence should be addressed (Tel/Fax: +81-52-735-5264, E-mail: takagi.koji@nitech.ac.jp). 


\section{EXPERIMENTAL}

\section{Instruments}

${ }^{1} \mathrm{H}$ and ${ }^{13} \mathrm{C}$ nuclear magnetic resonance (NMR) spectra were recorded on a Bruker Avance 200 FTNMR spectrometer using tetramethylsilane $\left({ }^{1} \mathrm{H}\right.$ NMR, $\delta 0.00)$ or $\mathrm{CDCl}_{3}\left({ }^{13} \mathrm{C} \mathrm{NMR}, \delta 77.0\right)$ as internal reference peaks. Infrared (IR) spectra were recorded on a Nicolet Impact 400D FT-IR spectrophotometer. Melting points were determined on a YANAGIMOTO micro melting point apparatus. Elemental analyses (EA) were performed by a Yanaco CHN Corder MT-3. Gel permeation chromatographic (GPC) analyses were carried out on a Tosoh DP-8020 using tandem TSK Multipore $\mathrm{H}_{\mathrm{XL}}-\mathrm{M}$ columns (THF as an eluent, flow rate $=1.0 \mathrm{~mL} / \mathrm{min}, 40^{\circ} \mathrm{C}$ ) equipped with a refractive index detector (RI-8010) on the basis of standard polystyrene samples. Ultraviolet (UV) and photoluminescence (PL) spectra were recorded on a Shimadzu UV-1650PC spectrophotometer and a Shimadzu RF$5300 \mathrm{PC}$ spectrofluorometer, respectively, using a $1 \mathrm{~cm}$ quartz cell or $1 \mathrm{~cm} \times 5 \mathrm{~cm}$ quartz plate. Quantum yields were determined relative to quinine sulfate in $0.1 \mathrm{~N} \mathrm{H}_{2} \mathrm{SO}_{4}$ with a quantum yield of 0.55 .

\section{Materials}

Cycloheptanone and boron tribromide were purchased from Kishida Chemical Co., Ltd. Sodium methoxide was purchased from Kanto Chemical Co. Tetrakis(triphenylphosphine)palladium $(0)\left[\mathrm{Pd}\left(\mathrm{PPh}_{3}\right)_{4}\right]$ was purchased from TCI. Palladium acetate $\left[\mathrm{Pd}(\mathrm{OAc})_{2}\right]$ was purchased from Wako Pure Chemical Industries Ltd. Dichlorobis(triphenylphosphine)palladium(II) $\left[\mathrm{PdCl}_{2}\left(\mathrm{PPh}_{3}\right)_{2}\right]$ and 9,9-dihexylfluorene-2,7bis(trimethyleneborate) were purchased from Aldrich Chemical Co. These reagents were used as received. 2,7-Diethenyl-9,9-dihexylfluorene, ${ }^{8}$ 2,7-diethynyl-9,9dihexylfluorene, ${ }^{9} \quad$ 2,5-didecyloxybenzene-1,4-bis(boronic acid), ${ }^{10}$ 2,5-didecylbenzene-1,4-bis(boronic acid) ${ }^{11}$ were synthesized according to the reported protocols. All solvents were dried following to the standard methods and distilled under nitrogen before use. All reactions were performed under nitrogen unless otherwise stated.

\section{Monomer Synthesis}

Synthesis of 2,4,7-tribromotropone (1). To a mixture of cycloheptanone $(25.0 \mathrm{~g}, 223 \mathrm{mmol})$ and acetic acid $(50 \mathrm{~mL})$ in a three-necked flask equipped with a reflux condenser and a dropping funnel was slowly added bromine ( $143 \mathrm{~g}, 894 \mathrm{mmol})$ dissolved in acetic acid $(75 \mathrm{~mL})$ at $0{ }^{\circ} \mathrm{C}$. The reaction mixture was stirred for $12 \mathrm{~h}$ at room temperature and for $25 \mathrm{~h}$ at $50^{\circ} \mathrm{C}$. Bromine $(143 \mathrm{~g}, 894 \mathrm{mmol})$ in acetic acid $(50 \mathrm{~mL})$ was again added at $0{ }^{\circ} \mathrm{C}$ and the reaction was further performed for $12 \mathrm{~h}$ at room temperature and for $25 \mathrm{~h}$ at $80^{\circ} \mathrm{C}$. Acetic acid was distilled off and the remaining product was purified by column chromatography $\left(\mathrm{SiO}_{2}, \mathrm{CH}_{2} \mathrm{Cl}_{2}\right)$. Recrystallization from $\mathrm{CH}_{2} \mathrm{Cl}_{2} / n$ hexane gave $\mathbf{1}$ as a brown solid in $10.2 \mathrm{~g}$ (13.4\%). Mp. $185-186^{\circ} \mathrm{C} .{ }^{1} \mathrm{H}$ NMR $\left(200 \mathrm{MHz}, \mathrm{CDCl}_{3}\right) \delta(\mathrm{ppm})$ $8.42(1 \mathrm{H}, \mathrm{d}, J=1.70 \mathrm{~Hz}), 7.89(1 \mathrm{H}, \mathrm{d}, J=10.18$ $\mathrm{Hz}), 7.25(1 \mathrm{H}, \mathrm{dd}, J=1.70,10.18 \mathrm{~Hz}) .{ }^{13} \mathrm{C}$ NMR $(50$ $\left.\mathrm{MHz}, \mathrm{CDCl}_{3}\right) \delta(\mathrm{ppm})$ 173.9, 142.3, 138.0, 137.7, 137.5, 133.5, 127.9. IR (KBr) $\left(\mathrm{cm}^{-1}\right) 3049.4,1607.0$, $1577.6,1556.1,1397.2,1347.2,1210.6,1112.7$, 1017.5, 948.0, 885.4, 856.7, 749.1, 644.1, 567.5, 561.5, 499.8. Anal. Calcd. for: $\mathrm{C}_{7} \mathrm{H}_{3} \mathrm{Br}_{3} \mathrm{O}: \mathrm{C}, 24.53$; $\mathrm{H}, 0.88$. Found: C, 24.75; H, 0.99 .

Synthesis of n,7-dibromo methyltropolone (2) $(\mathrm{n}=$ 4 and 5). To a suspension of $1(5.00 \mathrm{~g}, 14.5 \mathrm{mmol})$ in methanol $(20 \mathrm{~mL})$ in a two-necked flask equipped with a reflux condenser was added sodium methoxide $(1.10 \mathrm{~g}, 21.8 \mathrm{mmol})$. After the exothermic reaction subsided, the mixture was refluxed for $5 \mathrm{~h}$, poured into aq. $\mathrm{NH}_{4} \mathrm{Cl}$, and extracted with $\mathrm{CH}_{2} \mathrm{Cl}_{2}$. An organic phase was dried over $\mathrm{MgSO}_{4}$ and the solvent was removed under the reduced pressure. The crude product was purified by column chromatography $\left(\mathrm{SiO}_{2}\right.$, $\mathrm{CH}_{2} \mathrm{Cl}_{2}$ ) to give 2 (an isomeric mixture of 4,7 and 5,7-dibromo methyltropolone) as pale yellow oil in $3.56 \mathrm{~g}(83.4 \%) .{ }^{1} \mathrm{H}$ NMR $\left(200 \mathrm{MHz}, \mathrm{CDCl}_{3}\right) \delta(\mathrm{ppm})$ $7.91(1 \mathrm{H} \times 0.62, \mathrm{~d}, J=2.31 \mathrm{~Hz}), 7.83(1 \mathrm{H} \times 0.38$, $\mathrm{d}, J=1.86 \mathrm{~Hz}), 7.67(1 \mathrm{H} \times 0.38, \mathrm{~d}, J=8.36 \mathrm{~Hz})$, 7.53-7.39 $(1 \mathrm{H} \times 2 \times 0.62+1 \mathrm{H} \times 0.38), 3.92(1 \mathrm{H} \times$ $0.62, \mathrm{~s}), 3.91(1 \mathrm{H} \times 0.38, \mathrm{~s}) .{ }^{13} \mathrm{C} \mathrm{NMR}(50 \mathrm{MHz}$, $\left.\mathrm{CDCl}_{3}\right) \delta(\mathrm{ppm})$ 165.6, 165.1, 136.8, 135.6, 135.4, $134.1,133.4,132.4,130.6,130.3,126.4,122.6$, $120.9,120.3,52.6,52.5$. IR $(\mathrm{KBr})\left(\mathrm{cm}^{-1}\right)$ 2956.9, $1736.6,1606.7,1575.4,1457.5,1433.9,1374.9$, $1347.4,1284.5,1245.2,1146.9,1111.6,1088.0$, 1029.0, 966.1, 887.5, 828.5, 769.5, 742.0.

\section{Polymerization Procedure}

Fluorene-Based Polymer. To a two-necked flask equipped with a reflux condenser containing $2(0.24 \mathrm{~g}$, $0.80 \mathrm{mmol}$ ) and 9,9-dihexylfluorene-2,7-bis(trimethyleneborate) $(0.40 \mathrm{~g}, 0.80 \mathrm{mmol})$ dissolved in THF $(18 \mathrm{~mL})$ were added $2 \mathrm{M}$ aq. $\mathrm{K}_{2} \mathrm{CO}_{3}(3.0 \mathrm{~mL})$ and $\mathrm{Pd}\left(\mathrm{PPh}_{3}\right)_{4}(0.09 \mathrm{~g}, 0.08 \mathrm{mmol})$. The mixture was refluxed for $15 \mathrm{~h}$ and extracted with $\mathrm{CH}_{2} \mathrm{Cl}_{2}$. The solvent was evaporated to give a crude product, which was purified by the precipitation into methanol. After drying for $6 \mathrm{~h}$ at $50^{\circ} \mathrm{C}$, poly $(9,9$-dihexylfluorenylidene-alt-methyltropolone) (HFMTp) was obtained as a pale yellow powder in $0.30 \mathrm{~g}(80 \%) . M_{\mathrm{n}}=10400$, $\mathrm{PDI}=2.4{ }^{1} \mathrm{H}$ NMR $\left(200 \mathrm{MHz}, \mathrm{CDCl}_{3}\right) \delta(\mathrm{ppm}) 8.14$ $7.34\left(9 \mathrm{H}\right.$, aromatic protons), $3.66\left(3 \mathrm{H}, \mathrm{OCH}_{3}\right), 2.05$ $\left(4 \mathrm{H}, \mathrm{CH}_{2} \mathrm{C}_{5} \mathrm{H}_{11}\right), 1.08\left(12 \mathrm{H}, \mathrm{CH}_{2} \mathrm{C}_{3} \mathrm{H}_{6} \mathrm{C}_{2} \mathrm{H}_{5}\right), 0.76$ 
$\left(10 \mathrm{H}, \mathrm{C}_{4} \mathrm{H}_{8} C_{2} H_{5}\right) . \mathrm{IR}(\mathrm{KBr})\left(\mathrm{cm}^{-1}\right)$ 2956.9, 2925.9, $2854.9,1732.0,1732.0,1600.6,1457.5,1433.9$, $1374.9,1284.5,1237.4,1135.1,1095.8,816.7$, 789.2 .

To a two-necked flask equipped with a vigreux column containing $2(0.22 \mathrm{~g}, 0.75 \mathrm{mmol}), 2,7$-diethenyl9,9-dihexylfluorene $(0.29 \mathrm{~g}, 0.75 \mathrm{mmol})$, and sodium acetate $(0.31 \mathrm{~g}, 2.3 \mathrm{mmol})$ dissolved in NMP $(6 \mathrm{~mL})$ was added $\mathrm{Pd}(\mathrm{OAc})_{2}(0.017 \mathrm{~g}, 0.075 \mathrm{mmol})$. The mixture was heated at $130^{\circ} \mathrm{C}$ for $2 \mathrm{~d}$ and poured into methanol. The precipitate was collected and dried to obtain poly(9,9-dihexylfluorenylidenevinylene-altmethyltropolone) (HFVMTp) as a yellow powder in $0.14 \mathrm{~g}(36 \%) . M_{\mathrm{n}}=2800, \mathrm{PDI}=2.1{ }^{1} \mathrm{H}$ NMR $(200$ $\left.\mathrm{MHz}, \mathrm{CDCl}_{3}\right) \delta(\mathrm{ppm}) 7.91-6.98(13 \mathrm{H}$, unsaturated protons), $3.66\left(3 \mathrm{H}, \mathrm{OCH}_{3}\right), 2.02\left(4 \mathrm{H}, \mathrm{CH}_{2} \mathrm{C}_{5} \mathrm{H}_{11}\right)$, $1.08\left(12 \mathrm{H}, \mathrm{CH}_{2} \mathrm{C}_{3} \mathrm{H}_{6} \mathrm{C}_{2} \mathrm{H}_{5}\right), 0.74\left(10 \mathrm{H}, \mathrm{C}_{4} \mathrm{H}_{8} \mathrm{C}_{2} \mathrm{H}_{5}\right)$. IR $(\mathrm{KBr})\left(\mathrm{cm}^{-1}\right)$ 2925.5, 2854.1, 1708.6, 1691.3, 1596.8, 1465.6, 1259.3, 1205.3, 958.5, 821.5.

To a two-necked flask equipped with a vigreux column containing $2(0.22 \mathrm{~g}, 0.75 \mathrm{mmol})$ and 2,7-diethynyl-9,9-dihexylfluorene $(0.29 \mathrm{~g}, 0.75 \mathrm{mmol})$ dissolved in toluene $(14 \mathrm{~mL})$ and triethylamine $(5 \mathrm{~mL})$ were added $\mathrm{CuI}(0.014 \mathrm{~g}, 0.075 \mathrm{mmol})$ and $\mathrm{PdCl}_{2}-$ $\left(\mathrm{PPh}_{3}\right)_{2}(0.05 \mathrm{~g}, 0.075 \mathrm{mmol})$. The mixture was stirred at room temperature for $2 \mathrm{~h}$ and at $60^{\circ} \mathrm{C}$ for $3 \mathrm{~h}$, and poured into methanol. The precipitate was collected and dried to obtain poly(9,9-dihexylfluorenylideneethynylene-alt-methyltropolone) (HFEMTp) as a yellow powder in $0.33 \mathrm{~g}(81 \%) . M_{\mathrm{n}}=3800$, PDI $=2.1$ ${ }^{1} \mathrm{H}$ NMR $\left(200 \mathrm{MHz}, \mathrm{CDCl}_{3}\right) \delta(\mathrm{ppm}) 7.69-7.53(9 \mathrm{H}$, unsaturated protons), $4.02\left(3 \mathrm{H}, \mathrm{OCH}_{3}\right), 1.98(4 \mathrm{H}$, $\left.\mathrm{CH}_{2} \mathrm{C}_{5} \mathrm{H}_{11}\right), 1.07\left(12 \mathrm{H}, \mathrm{CH}_{2} \mathrm{C}_{3} \mathrm{H}_{6} \mathrm{C}_{2} \mathrm{H}_{5}\right), 0.81(6 \mathrm{H}$, $\left.\mathrm{C}_{5} \mathrm{H}_{10} \mathrm{CH}_{3}\right), \quad 0.64\left(4 \mathrm{H}, \mathrm{C}_{4} \mathrm{H}_{8} \mathrm{CH}_{2} \mathrm{CH}_{3}\right)$. IR (KBr) $\left(\mathrm{cm}^{-1}\right)$ 2950.6, 2925.5, 2854.1, 1733.7, 1718.3, $1592.9,1461.8,1432.9,1284.4,1261.2,1243.9$, 1095.4, 1074.2, 1025.9, 819.6, 802.2.

Benzene-Based Polymer. Poly(2,5-didecyloxyphenylene-alt-methyltropolone) (DOPMTp) and poly(2,5-didecylphenylene-alt-methyltropolone) (DPMTp) bearing 2,5-didecyloxy-1,4-phenylene and 2,5-didecyl-1,4-phenylene, respectively, were synthesized similarly by Suzuki coupling polymerization. DOPMTp: Yield $94 \% . \quad M_{\mathrm{n}}=8400$, PDI $=2.1{ }^{1} \mathrm{H}$ NMR $(200$ $\left.\mathrm{MHz}, \mathrm{CDCl}_{3}\right) \delta(\mathrm{ppm})$ 8.20-6.92 (5H, unsaturated protons), 3.97-3.87 (4H, $\left.\mathrm{OCH}_{2} \mathrm{C}_{9} \mathrm{H}_{19}\right), 3.74(3 \mathrm{H}$, $\left.\mathrm{OCH}_{3}\right), 1.73-1.63\left(4 \mathrm{H}, \mathrm{OCH}_{2} \mathrm{CH}_{2} \mathrm{C}_{8} \mathrm{H}_{17}\right), 1.23(28 \mathrm{H}$, $\left.\mathrm{OC}_{2} \mathrm{H}_{4} \mathrm{C}_{7} \mathrm{H}_{14} \mathrm{CH}_{3}\right), 0.86\left(6 \mathrm{H}, \mathrm{OC}_{9} \mathrm{H}_{18} \mathrm{CH}_{3}\right)$. IR $(\mathrm{KBr})$ $\left(\mathrm{cm}^{-1}\right)$ 2921.6, 2853.2, 1725.0, 1603.5, 1467.6, $1433.8,1375.0,1260.3,1204.3,1089.6,1019.2$, 794.5, 693.3. DPMTp: Yield 67\%. $M_{\mathrm{n}}=5900$, PDI $=1.9{ }^{1} \mathrm{H}$ NMR $\left(200 \mathrm{MHz}, \mathrm{CDCl}_{3}\right) \delta(\mathrm{ppm}) 8.00$ $7.05(5 \mathrm{H}$, unsaturated protons), $3.68(3 \mathrm{H}, \mathrm{OCH} 3)$, 2.62-2.47 (4H, $\left.\mathrm{CH}_{2} \mathrm{C}_{9} \mathrm{H}_{19}\right), 1.48\left(4 \mathrm{H}, \mathrm{CH}_{2} \mathrm{CH}_{2} \mathrm{C}_{8} \mathrm{H}_{17}\right)$, $1.21\left(28 \mathrm{H}, \mathrm{C}_{2} \mathrm{H}_{4} \mathrm{C}_{7} \mathrm{H}_{14} \mathrm{CH}_{3}\right), 0.85\left(6 \mathrm{H}, \mathrm{C}_{9} \mathrm{H}_{18} \mathrm{CH}_{3}\right)$.
IR $(\mathrm{KBr})\left(\mathrm{cm}^{-1}\right)$ 2933.3, 2847.1, 1733.7, 1720.2, 1600.6, 1465.4, 1433.9, 1288.5, 1241.3, 1084.0.

\section{Polymer Reaction (Transformation to $\mathrm{OH}$ Group)}

To a $\mathrm{CH}_{2} \mathrm{Cl}_{2}$ solution $(18 \mathrm{~mL})$ of HFMTp $(0.20 \mathrm{~g}$, $0.43 \mathrm{mmol}$ ) in a two-necked flask equipped with a reflux condenser was added $\mathrm{BBr}_{3}(0.38 \mathrm{~g}, 1.5 \mathrm{mmol})$ at $0^{\circ} \mathrm{C}$. After refluxing for $20 \mathrm{~h}$, the reaction mixture was poured into iced water and stirred for $1 \mathrm{~h}$. Extraction with $\mathrm{CH}_{2} \mathrm{Cl}_{2}$, washing with brine, drying over $\mathrm{MgSO}_{4}$, and evaporation of the solvent gave a crude product. The precipitation into methanol afforded poly(9,9-dihexylfluorenylidene-alt-tropolone) (HFTp) having a free hydroxyl group in $0.04 \mathrm{~g}$ $(21 \%)$ as a THF soluble part. $M_{\mathrm{n}}=9100, \mathrm{PDI}=2.4$ ${ }^{1} \mathrm{H}$ NMR $\left(200 \mathrm{MHz}, \mathrm{CDCl}_{3}\right) \delta(\mathrm{ppm}) 8.05-7.65(9 \mathrm{H}$, aromatic protons), $2.14\left(4 \mathrm{H}, \mathrm{CH}_{2} \mathrm{C}_{3} \mathrm{H}_{6} \mathrm{C}_{2} \mathrm{H}_{5}\right), 1.11$ $\left(12 \mathrm{H}, \mathrm{CH}_{2} \mathrm{C}_{3} \mathrm{H}_{6} \mathrm{C}_{2} \mathrm{H}_{5}\right), 0.86\left(10 \mathrm{H}, \mathrm{CH}_{2} \mathrm{C}_{3} \mathrm{H}_{6} C_{2} H_{5}\right)$. IR (KBr) $\left(\mathrm{cm}^{-1}\right)$ 2956.9, 2925.5, 2854.9, 1713.0, $1610.8,1599.0,1453.6,1426.0,1260.9,1170.5$, 1107.6, 1025.1, 820.6, 789.2. Poly(2,5-didecylphenylene-alt-tropolone) (DPTp) was likewise prepared in a quantitative yield. $M_{\mathrm{n}}=7900, \mathrm{PDI}=2.9{ }^{1} \mathrm{H}$ NMR $\left(200 \mathrm{MHz}, \mathrm{CDCl}_{3}\right) \delta(\mathrm{ppm}) 7.73-7.18(5 \mathrm{H}$, unsaturated protons), 2.97-2.66 $\left(4 \mathrm{H}, \mathrm{CH}_{2} \mathrm{C}_{9} \mathrm{H}_{19}\right), 1.75-$ $1.20\left(32 \mathrm{H}, \mathrm{CH}_{2} \mathrm{C}_{8} \mathrm{H}_{16} \mathrm{CH}_{3}\right), 0.86\left(6 \mathrm{H}, \mathrm{C}_{9} \mathrm{H}_{18} \mathrm{CH}_{3}\right)$. IR (KBr) $\left(\mathrm{cm}^{-1}\right) 3450.0,2936.0,2925.5,2847.1$, $1791.7,1704.8,1602.6,1453.6,1264.9,1186.2$, 1103.7, 804.9.

\section{RESULTS AND DISCUSSION}

\section{Polymerization and Characterization}

A tropolone derivative $\mathbf{2}$ was synthesized by the reaction of $\mathbf{1}$ with sodium methoxide in methanol under the refluxed temperature. The nucleophilic reaction occurred both at 2 and 7-position to give an isomeric mixture of 4,7 and 5,7-dibromo methyltropolone, where the molar ratio was determined to be $43: 57$ from the integral ratio of the ${ }^{1} \mathrm{H}$ NMR spectrum. They were directly subjected to the polymerization because the single isomer could not be isolated. Three fluorene-based conjugated polymers with a protected hydroxyl group (HFMTp, HFVMTp, and HFEMTp) were synthesized by the typical Suzuki coupling, Mizoroghi-Heck, and Sonogashira coupling reactions (Scheme 1). Polymers were obtained as a pale yellow or a yellow powder in good yields. HFMTp showed a good solubility in organic solvents to have the highest number-averaged molecular weight $\left(M_{\mathrm{n}}=10400\right)$ calculated from the GPC analysis, which corresponded to repeating unit of 22. HFVMTp and HFEMTp were less soluble and the molecular weights were smaller than HFMTp. The polymer structure was confirmed by the ${ }^{1} \mathrm{H}$ NMR spectra. A characteristic 

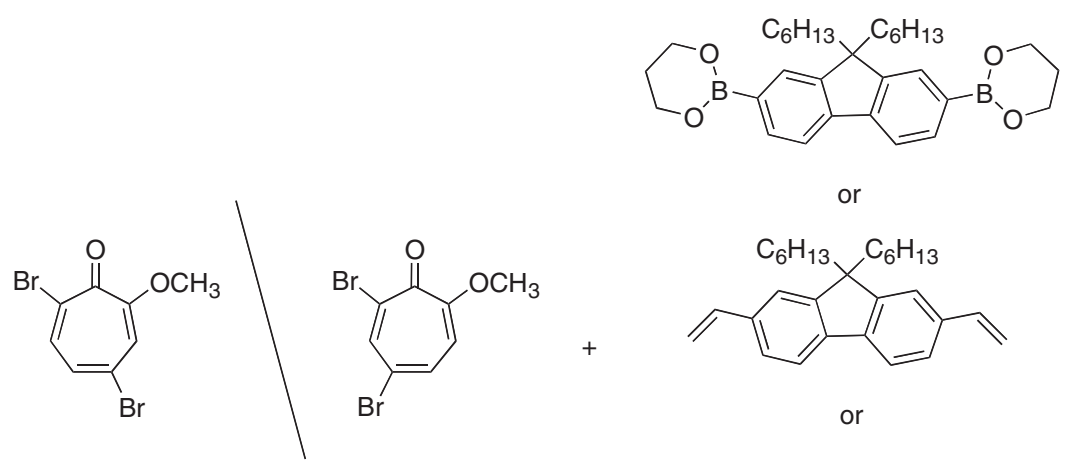

or

2 (mixture)
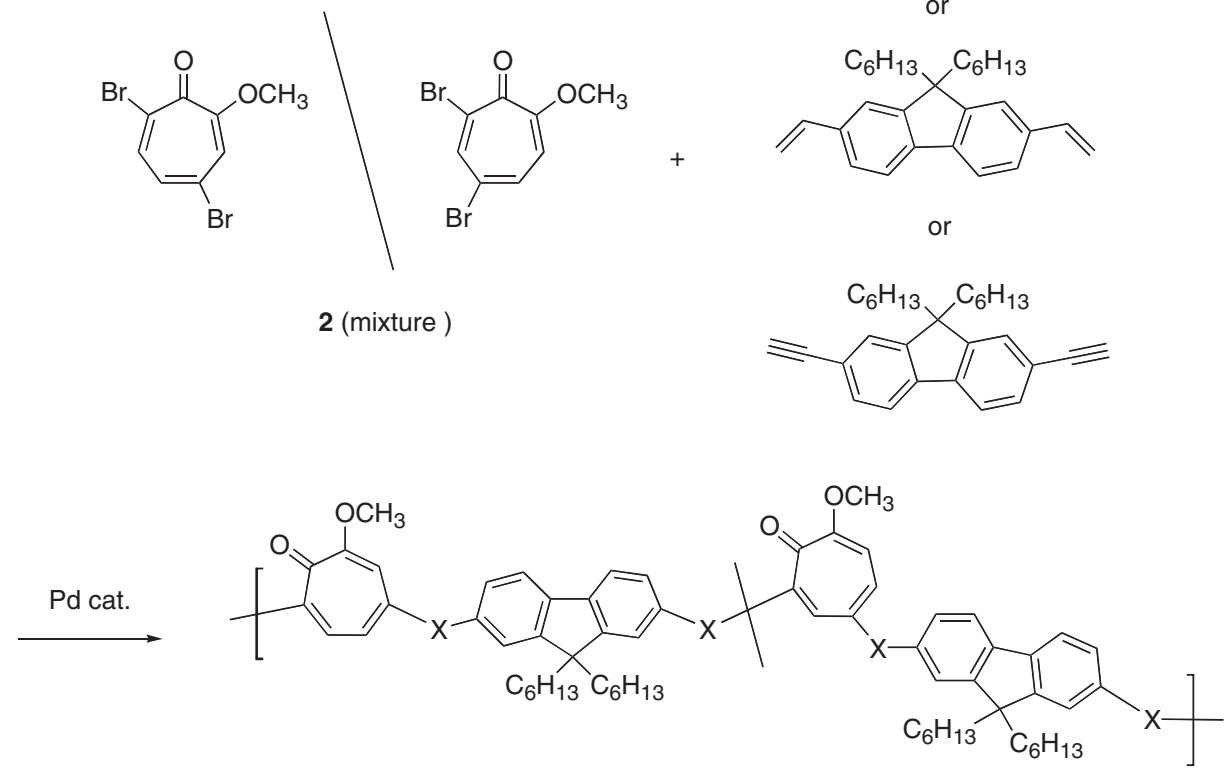

HFMTp (X = nil), HFVMTp (X = vinylene), and HFEMTp ( $\mathrm{X}=$ ethynylene)

Scheme 1.

signal of tropolone in HFMTp was observed at 8.14 ppm, which shifted to downfield region as compared with 2 (Figure 1a). Although the chemical reactivity of two isomers of $\mathbf{2}$ was expected to be different, the ratio of two repeating unit in these polymers could not be determined. In the IR spectrum of HFVMTp, the signal assignable to the $\mathrm{C}-\mathrm{H}$ out-of-plane bending mode was found at $958 \mathrm{~cm}^{-1}$ to indicate that the polymer mainly consisted of trans vinylene structure. The $\mathrm{C}=\mathrm{O}$ stretching vibration signals were observed at $1730 \mathrm{~cm}^{-1}, 1710 \mathrm{~cm}^{-1}$, and $1734 \mathrm{~cm}^{-1}$ for HFMTp, HFVMTp, and HFEMTp, respectively. Those signals shifted to the lower frequency region as compared with monomer $2\left(1740 \mathrm{~cm}^{-1}\right)$, which agreed with our previous reports about conjugated polymers having (benzo)tropone in the main chain. . $^{3 c, 3 e}$

The conversion from the methoxy group to the hydroxyl group was carried out by using $\mathrm{BBr}_{3}$ (Scheme 2). HFVTp and HFETp became insoluble in organic solvents probably due to the rigid main chain forced by the intramolecular hydrogen bond within the tropolone unit. From the IR spectrum of HFVTp, for example, the $\mathrm{O}-\mathrm{H}$ vibration signal was observed at $3437 \mathrm{~cm}^{-1}$ and the $\mathrm{C}=\mathrm{O}$ vibration signal $\left(1704 \mathrm{~cm}^{-1}\right)$ shifted to the lower frequency region as compared with HFVMTp. This result supported the formation of an intramolecular hydrogen bond. On the other hand, HFTp mostly dissolved in THF, $\mathrm{CHCl}_{3}$, and toluene to have the number-averaged molecular weight of 9100 . In the ${ }^{1} \mathrm{H}$ NMR spectrum, the proton signal of methoxy group at $3.66 \mathrm{ppm}$ completely disappeared and that of tropolone at $8.14 \mathrm{ppm}$ shifted to upfield region to be observed at $7.99 \mathrm{ppm}$ (Figure 1b). The shift of the $\mathrm{C}=\mathrm{O}$ vibration signal from $1730 \mathrm{~cm}^{-1}$ to $1714 \mathrm{~cm}^{-1}$ in the IR spectra indicated the formation of an intramolecular hydrogen bond.

DOPMTp and DPMTp having the 1,4-phenylene segment were likewise obtained by Suzuki coupling polymerization catalyzed by $\mathrm{Pd}\left(\mathrm{PPh}_{3}\right)_{4}$ as pale yellow powders in good yields and they had a better solubility than HFMTp (Scheme 3). The number-averaged molecular weights of DOPMTp and DPMTp were estimated by GPC to be 8400 and 5900, respectively. In the ${ }^{1} \mathrm{H}$ NMR spectrum of DOPMTp, the signal of methylene proton adjacent to the oxygen atom split into two parts at $3.97 \mathrm{ppm}$ and $3.95 \mathrm{ppm}$ that reflected the two kinds of repeating unit. The similar trend was observed for the spectrum of DPMTp, where the methylene proton signal adjacent to the phenyl ring was detected at $2.62 \mathrm{ppm}$ and $2.47 \mathrm{ppm}$ (Figure 2a). The $\mathrm{C}=\mathrm{O}$ stretching vibration signals were observed at $1725 \mathrm{~cm}^{-1}$ and $1734 \mathrm{~cm}^{-1}$ for DOPMTp and DPMTp, respectively.

The conversion from the methoxy group of DOPMTp to the hydroxyl group was conducted by 
a

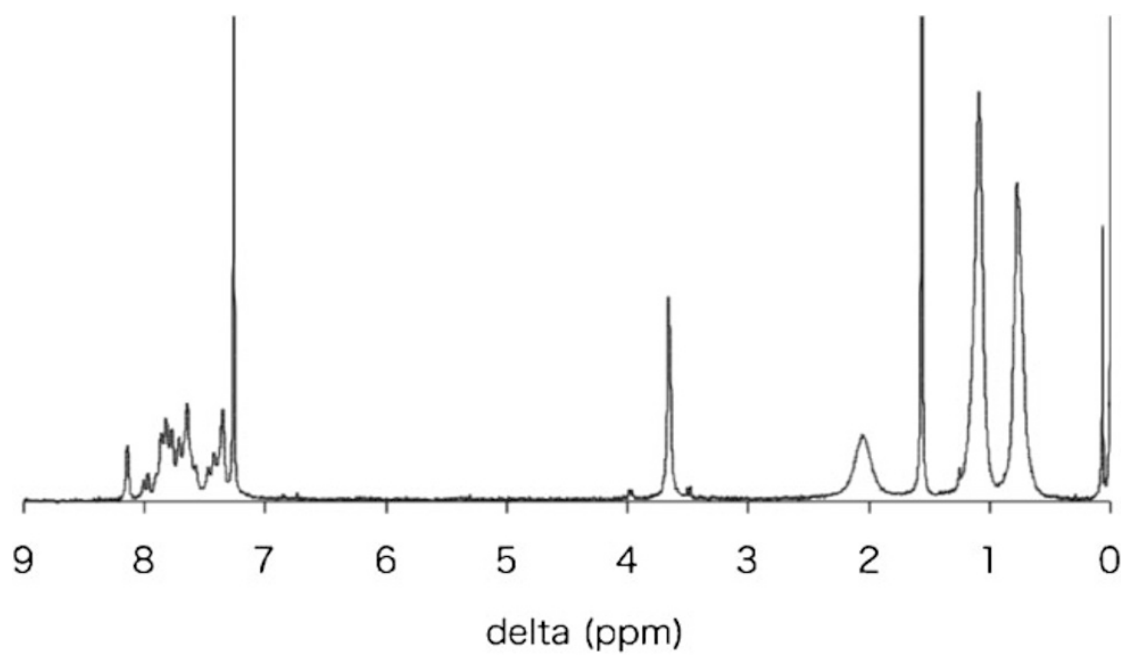

b

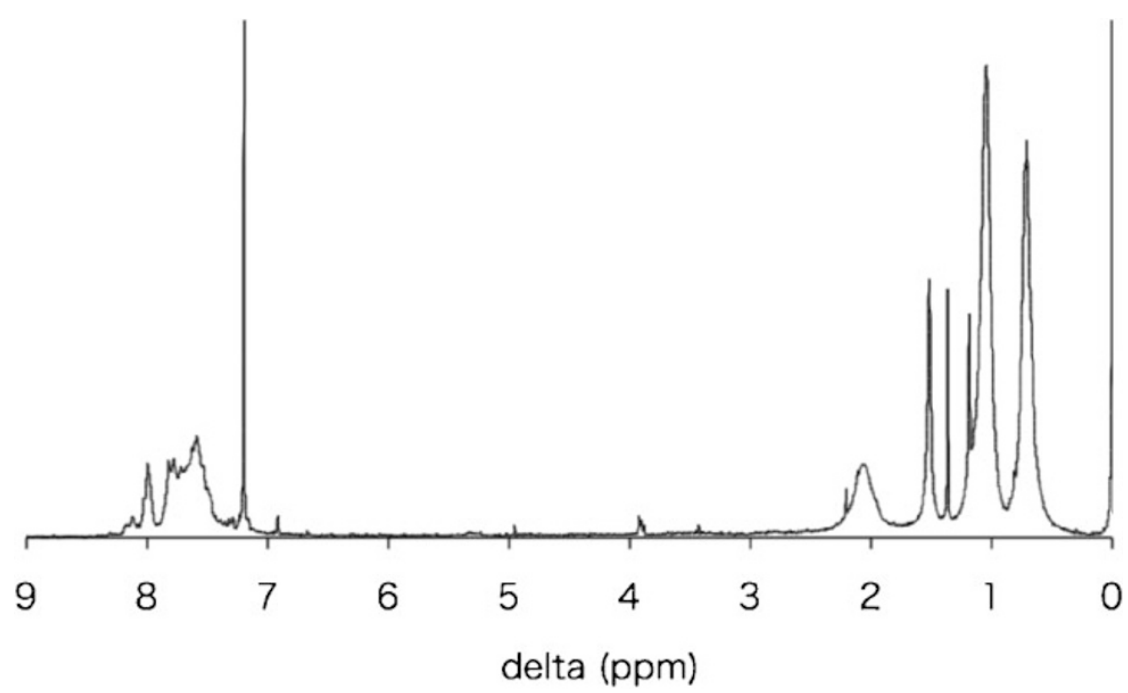

Figure 1. ${ }^{1} \mathrm{H}$ NMR spectra of (a) HFMTp and (b) HFTp in $\mathrm{CDCl}_{3}(200 \mathrm{MHz})$.<smiles>[X]c1ccc(C(C)(C)C)c(=O)c(OC)c1</smiles><smiles>[X]c1ccc2c(c1)C([13CH3])([13CH3])c1cc([X])ccc1-2</smiles>

$\operatorname{HFTp}(\mathrm{X}=$ nil), HFVTp (X = vinylene), and HFETp (X = ethynylene)

Scheme 2. 

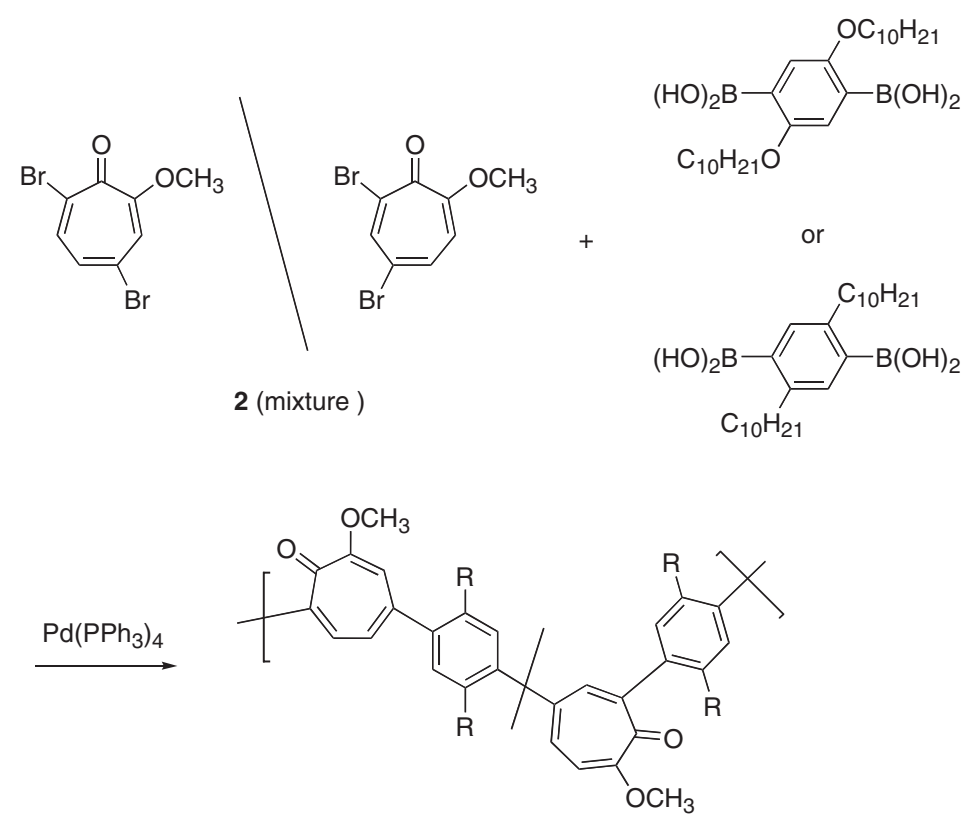

DOPMTp $\left(\mathrm{R}=\mathrm{OC}_{10} \mathrm{H}_{21}\right)$ and DPMTp $\left(\mathrm{R}=\mathrm{C}_{10} \mathrm{H}_{21}\right)$

Scheme 3.

LiI according to the previous report. ${ }^{12}$ Unfortunately, the insoluble product was obtained and the C-O-C vibration signal at $1260 \mathrm{~cm}^{-1}$ obviously decreased in the IR spectrum. We consider that the decyloxy chain was removed from the polymer backbone, probably due to the increased nucleophilicity of iodide anion caused by the coordination of lithium cation to tropolone. The close distance between the decyloxy chain and tropolone might be another important factor. In contrast, soluble DPTp could be obtained by using $\mathrm{BBr}_{3}$ (Scheme 4). The methoxy proton signal at $3.68 \mathrm{ppm}$ completely disappeared in the ${ }^{1} \mathrm{H}$ NMR spectrum (Figure $2 \mathrm{~b}$ ) and the $\mathrm{C}=\mathrm{O}$ stretching vibration shifted to the lower frequency region from DPMTp $\left(1734 \mathrm{~cm}^{-1}\right)$ to DPTp $\left(1707 \mathrm{~cm}^{-1}\right)$. This result supported the formation of a five-membered intramolecular hydrogen bond within the tropolone unit.

\section{Optical Properties}

The UV and PL spectra of methyltropolonecontaining fluorene-based conjugated polymers (HFMTp, HFVMTp, and HFEMTp) were measured in a $\mathrm{CHCl}_{3}$ solution $\left(10^{-6} \mathrm{M}\right)$. The absorption maximum wavelength red shifted in the order of HFMTp $(352 \mathrm{~nm})<$ HFEMTp $(387 \mathrm{~nm})<$ HFVMTp (395 $\mathrm{nm}$ ) (Figure 3), which followed the normal trend observed in other conjugated polymers. The absorption maximum of HFMTp blue shifted by $36 \mathrm{~nm}$ as compared with poly(9,9-dihexyl-2,7-fluorene) $(388 \mathrm{~nm})$. The emission maximum wavelength also red shifted in the same order. The fluorescence quantum yield was highest for HFMTp (0.68) and dropped to 0.28 of HFEMTp based on quinine sulfate as a standard (0.55). In the optical spectra of methyltropolonecontaining benzene-based conjugated polymers in a $\mathrm{CHCl}_{3}$ solution $\left(10^{-6} \mathrm{M}\right)$, DOPMTp had longer absorption $(350 \mathrm{~nm})$ and emission $(447 \mathrm{~nm})$ maximum wavelengths than those of DPMTp (269 nm and 385 $\mathrm{nm}$, respectively) (Figure 4), which stemmed from the intramolecular charge transfer between electron donor (decyloxybenzene) and electron acceptor (tropolone). The lower $\mathrm{C}=\mathrm{O}$ stretching vibration signal of DOPMTp $\left(1725 \mathrm{~cm}^{-1}\right)$ than DPMTp (1734 $\mathrm{cm}^{-1}$ ) also supported the presence of the intramolecular charge transfer. The fluorescence quantum yields (0.01 for DOPMTp and 0.05 for DPMTp) were lower than those of fluorene-based conjugated polymers, which agreed with the large Stokes shift as much as $116 \mathrm{~nm}$ and $95 \mathrm{~nm}$ for DOPMTp and DPMTp, respectively.

Finally, the influence of a free-hydroxyl group upon the optical properties of conjugated polymers was investigated with HFTp and DPTp having the enough solubility to obtain the optical spectra. When the methoxy group was converted to the hydroxyl group, the UV absorption spectra shifted to the longer wavelength region. Namely, the absorption maximum wavelengths of HFTp and DPTp were observed at $390 \mathrm{~nm}$ and $302 \mathrm{~nm}$, respectively (Figure 5). The cut-off wavelength was observed at considerably longer region $(550 \mathrm{~nm}$ for HFTp and $515 \mathrm{~nm}$ for DPTp). These bathochromic shifts might be ascribed 


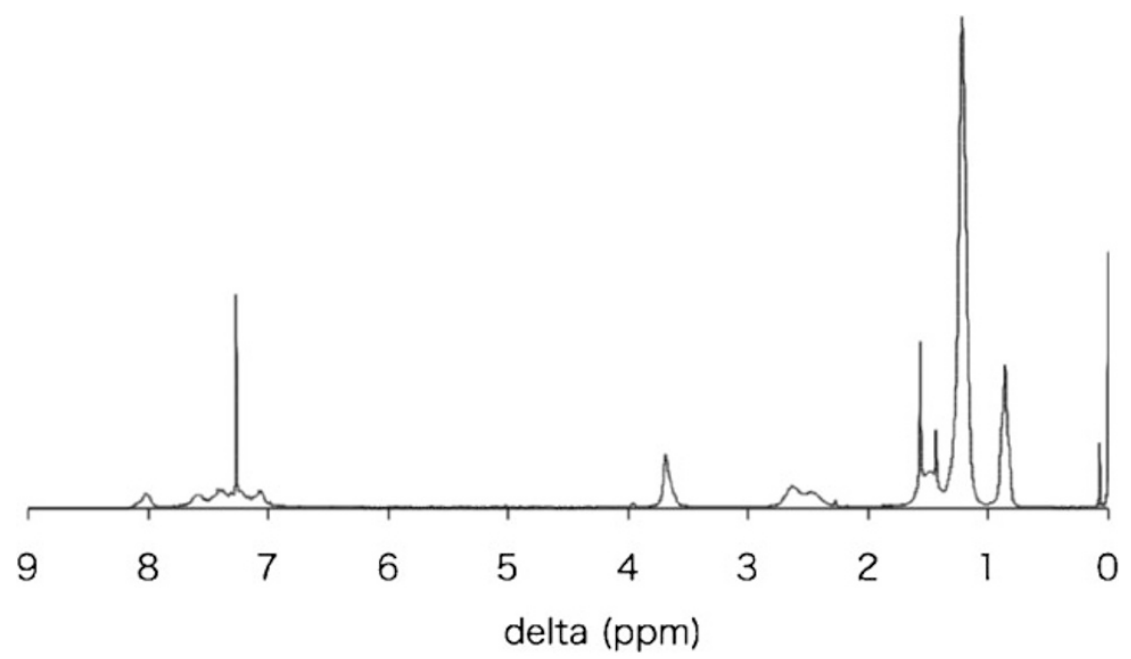

b

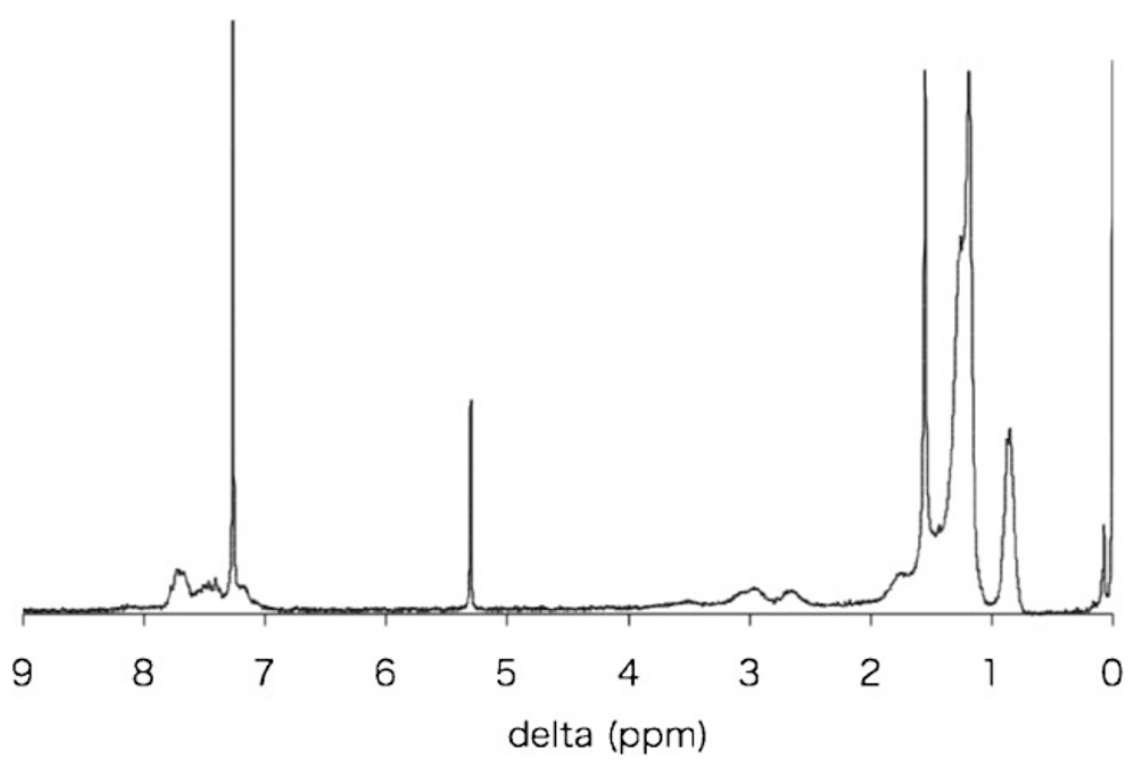

Figure 2. ${ }^{1} \mathrm{H}$ NMR spectra of (a) DPMTp and (b) DPTp in $\mathrm{CDCl}_{3}(200 \mathrm{MHz})$.
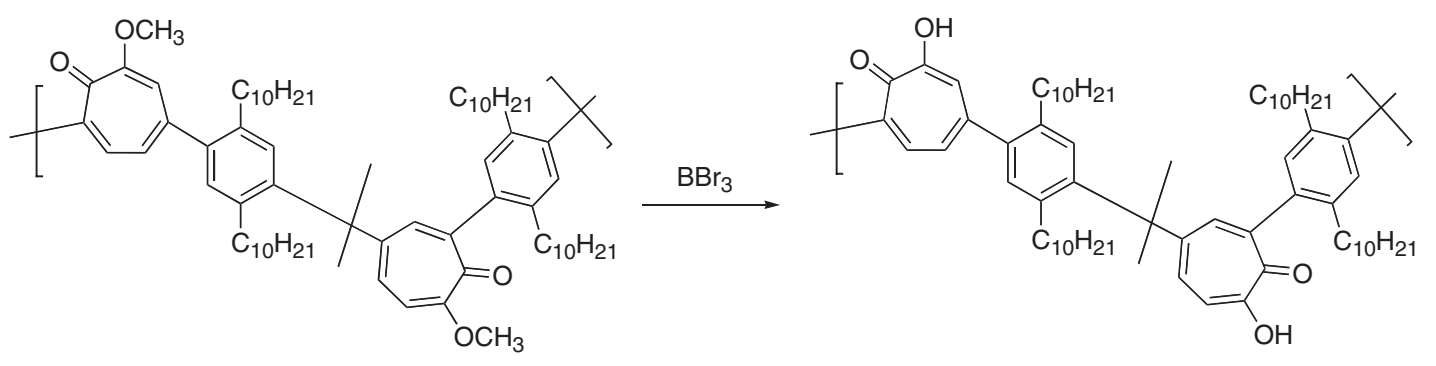

DPTp

Scheme 4.

to the formation of an intramolecular hydrogen bond between the hydroxyl group and the carbonyl oxygen, which forces the polymer chain more planar to elongate the effective conjugation length. The fluores- cence emissions were almost quenched in both polymers probably due to the non-radiative decay as observed in the protonation experiment of the benzotropone-containing conjugated polymer. ${ }^{3 c}$ 


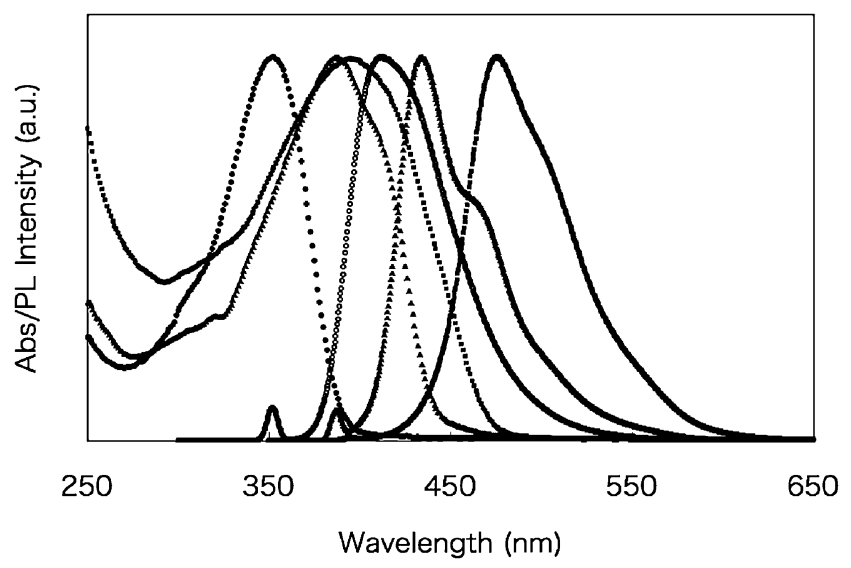

Figure 3. UV and PL spectra of methyltropolone-containing fluorene-based conjugated polymers in $\mathrm{CHCl}_{3}$. Closed circle: HFMTp (UV), Open circle: HFMTp (PL), Closed square: HFVMTp (UV), Open square: HFVMTp (PL), Closed triangle: HFEMTp (UV), and Open triangle: HFEMTp (PL).

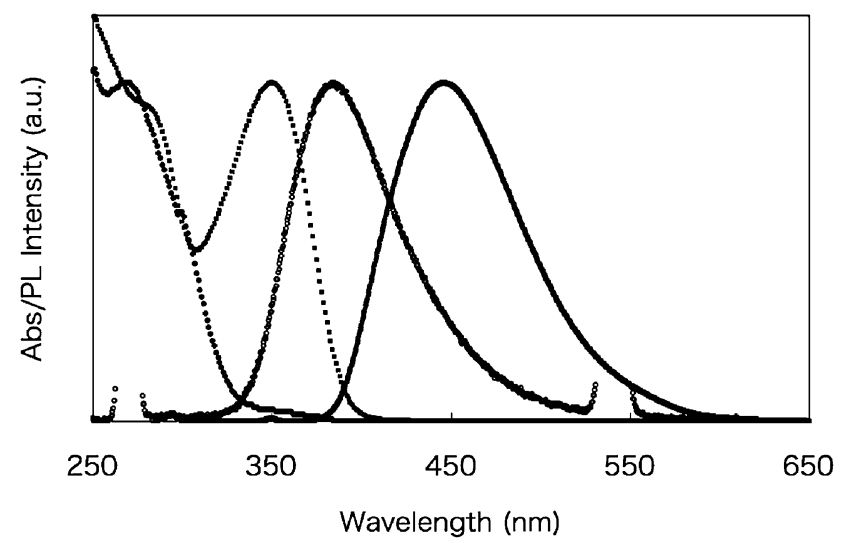

Figure 4. UV and PL spectra of methyltropolone-containing benzene-based conjugated polymers in $\mathrm{CHCl}_{3}$. Closed circle: DPMTp (UV), Open circle: DPMTp (PL), Closed square: DOPMTp (UV), and Open square: DOPMTp (PL).

\section{REFERENCES}

1. a) A. Kraft, A. C. Grimsdale, and A. B. Holmes, Angew. Chem. Int. Ed., 37, 402 (1998).

b) J. M. Goldenberg, M. R. Bryce, and M. C. Petty, J. Mater. Chem., 9, 1957 (1999).

c) J. M. Tour, Acc. Chem. Res., 33, 791 (2000).

d) R. P. Kingsborough and T. M. Swager, Prog. Inorg. Chem., 48, 123 (1999).

2. a) K. Sugiyasu, C. Song, and T. M. Swager, Macromolecules, 39, 5598 (2006).

b) E. E. Havinga, W. Hoeve, and H. Wynberg, Synth. Met., 55, 299 (1993).

3. a) K. Takagi, Y. Nishikawa, H. Kunisada, and Y. Yuki, Chem. Lett., 12, 1244 (2001).

b) K. Takagi, Y. Nishikawa, N. Nishioka, H. Kunisada, and Y. Yuki, J. Polym. Sci., Part A: Polym. Chem., 40, 3927 (2002).

c) K. Takagi, K. Mori, T. Kinoshita, H. Kunisada, and Y.

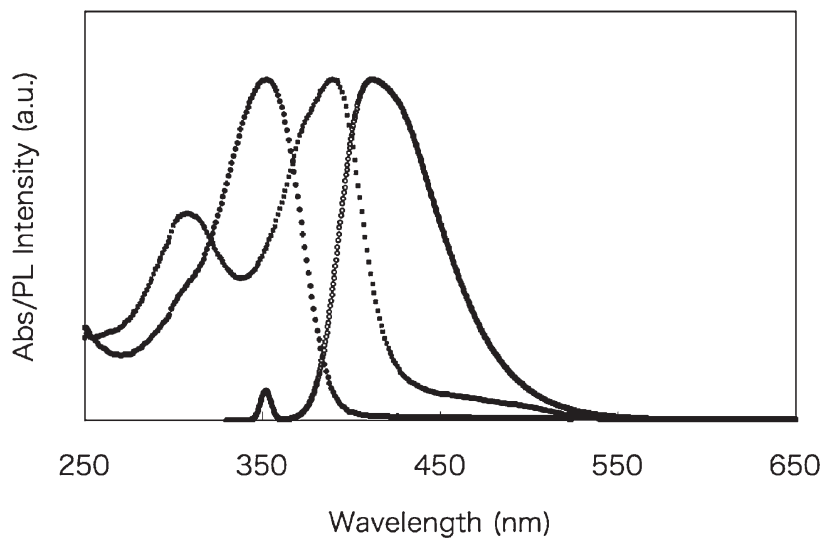

b

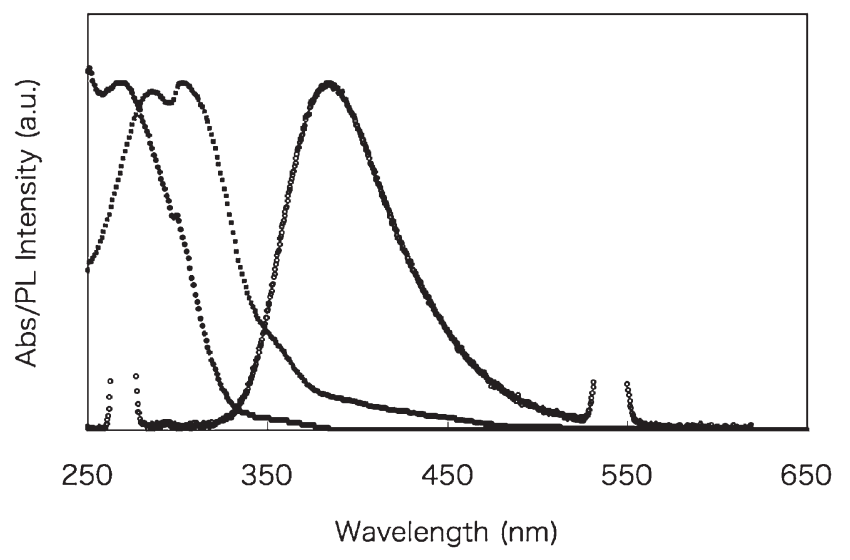

Figure 5. UV and PL spectra of (a) tropolone-containing fluorene-based conjugated polymers (Closed circle: HFMTp (UV), Open circle: HFMTp (PL), and Closed square: HFTp (UV)) and (b) tropolone-containing benzene-based conjugated polymers (Closed circle: DPMTp (UV), Open circle: DPMTp (PL), and Closed square: DPTp (UV)) in $\mathrm{CHCl}_{3}$.

Yuki, Chem. Lett., 32, 552 (2003).

d) N. Nishioka, K. Takagi, T. Kinoshita, H. Kunisada, and Y. Yuki, J. Polym. Sci., Part A: Polym. Chem., 42, 1208 (2004).

e) K. Takagi, K. Mori, H. Kunisada, and Y. Yuki, Polym. Bull., 52, 125 (2005).

4. a) D. W. J. Cruickshank, G. Filippini, and O. S. Mills, J. Chem. Soc., Chem. Commun., 2, 101 (1972).

b) M. J. Barrow and O. S. Mills, J. Chem. Soc., Chem. Commun., 3, 61 (1973).

c) D. J. Bertelli and T. G. Andrews, Jr. J. Am. Chem. Soc., 91, 5280 (1969). See, also: A. Streitwieser, Jr., "Molecular Orbital Theory for Organic Chemists," John Wiley \& Sons, Inc., N. Y., 1961, p 279.

5. a) M. Takemoto, A. Mori, and S. Ujiie, Chem. Lett., 11, 1177 (1999).

b) M. Hashimoto, S. Ujiie, and A. Mori, Chem. Lett., 7, 758 (2000).

6. a) M. J. Cook and E. J. Forbes, Tetrahedron, 24, 4501 (1968). 
b) W. von E. Doering and L. H. Knox, J. Am. Chem. Soc., 72, 2305 (1950).

c) H. Shimanouchi and Y. Sasada, Acta Crystallogr., B 29, 81 (1973).

7. a) D. A. P. Delnoye, R. P. Sijbesma, J. A. J. M. Vekemans, and E. W. Meijer, J. Am. Chem. Soc., 118, 8717 (1996).

b) A. P. Monkman, L.-O. Pålsson, R. W. T. Higgins, C. Wang, M. R. Bryce, A. S. Batsanov, and J. A. K. Howard, J. Am. Chem. Soc., 124, 6049 (2002).

c) S. Hou, M. Ding, and L. Gao, Macromolecules, 36, 3826 (2003).

d) T. Yasuda and T. Yamamoto, Macromolecules, 36, 7513 (2003). e) H. Tong, L. Wang, X. Jing, and F. Wang, Macromolecules, 36, 2584 (2003).

f) G. Zhou, Y. Cheng, L. Wang, X. Jing, and F. Wang, Macromolecules, 38, 2148 (2005).

8. O. Mongin and A. Gossauer, Tetrahedron, 53, 6835 (1997).

9. O. Mongin, L. Porres, L. Moreaux, J. Mertz, and M. B. Desce, Org. Lett., 4, 719 (2002).

10. S.-C. Ng, H.-F. Lu, H. S. O. Chan, A. Fujii, T. Laga, and K. Yoshino, Macromolecules, 34, 6895 (2001).

11. M. Rehahn, A.-D. Schlüter, and G. Wegner, Makromol. Chem., 191, 1991 (1990).

12. T. Yasuda and T. Yamamoto, Macromolecules, 36, 7519 (2003). 